\title{
الاستشهاد بالقرآن الكريم وقراءاته في كتاب الإنصاف في مسائل الحخلاف للأنباري \\ دراسة وصفية تحليلية
}

Sundus Muhammad Ahmed Khalifa

Abdulwasiu Isiaq Nasirudeen

جامعة المدينة العالمية_ ماليزيا

sundus.9385@gmail.com

Abdul.wasiu@mediu.edu.my

$$
\begin{aligned}
& \text { ملخص البحث } \\
& \text { تمدف هذه الورقة إلى الوقوف على أصلٍ من الأصول السماعية وهو القرآن الكريم وقراءاته في كتاب (الإنصاف في } \\
& \text { مسائل الخلاف)، وملى اعتماد الأنباري عليه في الموازنة بين البصريين والكوفيين، ثيَّ الخروج بصورة واضحة تكشف عن } \\
& \text { موقف الأنباري من الاحتجاج بالقرآن وقراءاته، وهل يُصنَّف من المانعين للاستشهاد بالقراءات أم المجيزين ؟، وبناءً على لى } \\
& \text { هذه الأهدف انتهجت الباحثة المنهج الوصفي التحليلي لتناسبه مع طبيعة هذه الظاهرة، والذي يقوم على وصف موقف } \\
& \text { الأنباري من القرآن وقراءاته من خلال توظيف القراءات في مسائل كتابه، وقد توصلت الدراسة إلى أنَّ الأنباري كان } \\
& \text { مُقلّاً في استشهاده بالحميث النبوي، حيث سار مع مذهب الجمهور في عدمِ الأخذِ بالحديث، والاعتدادِ به، إلا أنّه لمج } \\
& \text { يصرّح بذلك بل اكتفى بمجرد التلميح. } \\
& \text { الكلمات المفتاحية: الاستشهاد، كتاب الإنصاف، الأنباري }
\end{aligned}
$$

\begin{abstract}
The purpose of this paper is to identify the origin of the audio assets, the Holy Quran and its readings in the book Al-Insaffi Masail al-Khilaf" and the extent to which Al-Anbari relied on it in the balance between the Basrians and the Kufis, and then the exit clearly reveals the position of AlAnbari from the invocation of the Koran and its readings, and whether it is classified as a proponent of quotations or Almgizin ?, Based on these goals, the researcher pursued the analytical descriptive method to suit the nature of this phenomenon, which is based on the description of the position of Al-Anbari of the Koran And the reading through the use of readings in the issues of writing, and the study has concluded that Al-Anbari was quoted in the martyrdom of the Prophet, where he walked with the doctrine of the jumhur who did not taked the hadist, and admiration, but he did not say it, and only hinted it.
\end{abstract}

\section{Keywords: Citation, Al Inshaf, Al Anbari}


مدخل

يُعَدُّ أبو البركات كمال الدين الأنباري المتوفى سنة (ovV) من أشهر علماء اللغة والنحو، وقد تمتع الأنباري بكثير من العلوم التي شملت معظم علوم عصره، إلَّا أنّه قد شهر باللغة والنحو والأدب، وتُعَلُّ مصنفاته في هذه العلوم من أشهر ما يكون، ووِن أهم مصنفاته تلك الرسالتان اللتان وضعهما في علم أصول النحو: (الإغراب في جدل الإعراب) و (لمع الأدلة في أصول النحو)، كما يُعّدُّ كتابه (الإنصاف في مسائل الخلاف بين البصريين والكوفيين) من أشهر كتب الخلاف النحوي، ذلك الكتاب الذي ذاع صيته وطار ذكره في الآفاق، ويُعَدّ هذا الكتاب موطن الدراسة.

مشكلة البحث:

لا شكَّ في أن البحث في جانب الأصول النحوية أمر في غاية الأهمية، إذ هي الركن الركين في علم النحو، بيد أن المتتبع لذلك يجد أنَّ هناك حاجة لمزيد من الدراسات التي تتناول أصول النحو، لا سيَّما من الناحية العملية التطبيقية، ومن هنا أرداتِ الباحثةُ البحثَ في هذا الجانب المهم الذي قلَّ النظرُ فيه تطبيقيّا، حيث ظهرت لديها رغبة في الوقوف على شيء من الأصول النحوية في كتاب (الإنصاف) خاصة بعد أن وقفتْ على الدور الكبير لصاحبه في تأصيل علم أصول النحو.

أسئلة البحث:

1 - هل أكثر الأنباري من الاستشهاد بالقرآن الكريم في كتابه (الإنصاف)؟ r - ما موقف الأنباري من الاستشهاد بالقراءات القرآنية؟

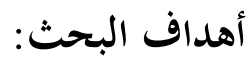

- - - موقف الأنباري من الاستشهاد بالقرآن الكريم.

r - موقف الأنباري من الاستشهاد القراءات القرآنية.

أهمية البحث:

تبرز أهمية هذا البحث من أهمية الأصول النحوية في تقرير القواعد وضبطها، لا سيّما القرآن الكريم وقراءاته، وقد آثرتُ كتاب (الإنصاف) ليكون موضع الدراسة؛ نظراً لأهميته وشموله لأكثر المسائل الخلافية في النحو، لا سيّما وأنَّ نظرة النحاة المتباينة لأصول النحو كانت عاملاً رئيسياً في اختلافهم. هذا فضلاً عن صاحب الكتاب الذي كان له دور في تأصيل علم أصول النحو، والوصول به إلى مرحلة النضج لهابن والاكتمال، حيث أفرد له مصنفاً مستقلاً يشتمل على إضافات جديدة في جانب التعريفات والتقسيمات، فأرسى بذلك مبادئ هذا العلم وقواعده في رسالته الشهيرة (لمع الأدلة في أصول النحو)، معَّا جعلها مرجعاً أساسياً من مراجع أصول النحو.

ومما زادني رغبةً في هذا البحث ما لاحظته من حاجة ميدان البحث العلمي للدراسات التي تتناول أص+ول النحو بالدراسة العملية التطبيقية. 
المنهج المتبع:

لعلّ المنهج المناسب لهده الدراسة هو المنهج الوصفي التحليلي؛ إذ يقوم على وصف موقف الأنباري من القرآن

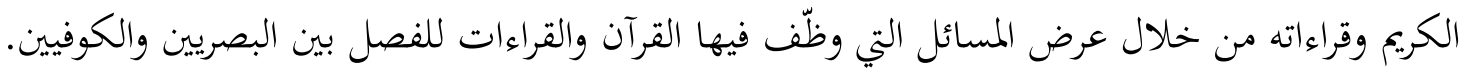

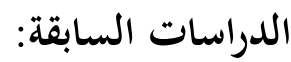

\section{أصول النحو دراسة في فكر الأنباري}

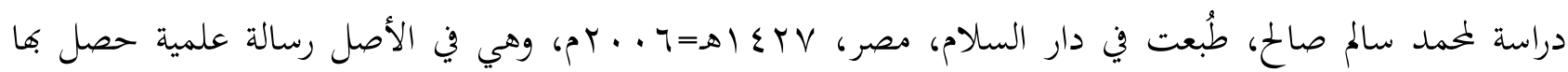

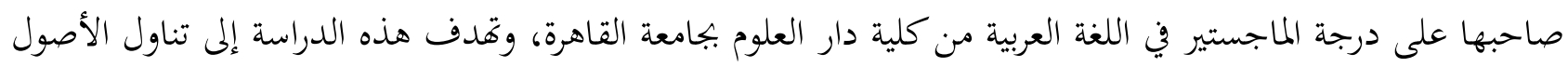
النحوية عند الأنباري بصورة متكاملة.

ووجه التشابه مع هذه الدراسة يكمن في دراسة الأصول النحوية عند الأنباري، أما الفرق بينهما فيتمثَّل في أنَّ النّا

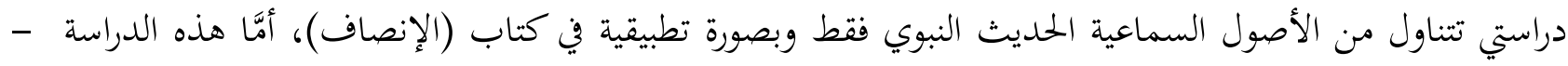

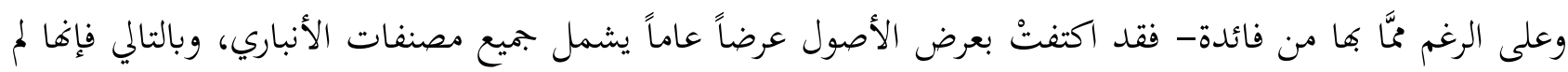

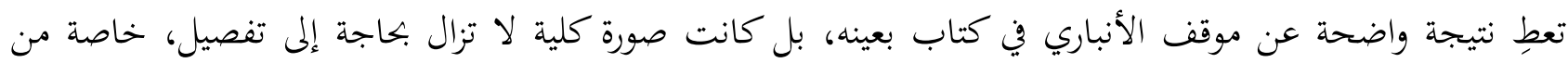

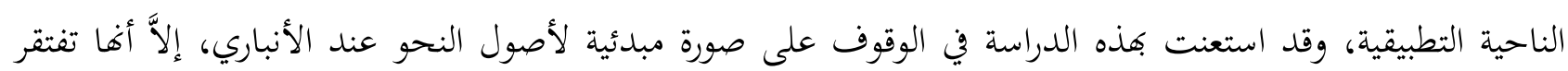

$$
\text { لشئ من الدقة والثفصيل في الجانب التطبيقي. }
$$

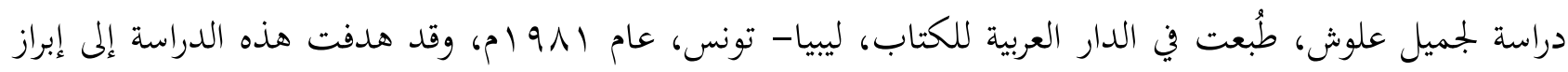

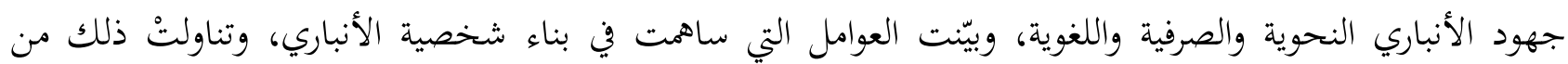

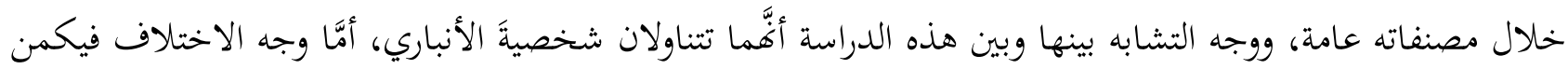

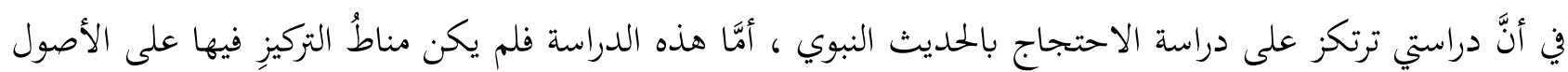
النحوية، وقد استعانت الباحثة بهذه الدراسة في الوقوف على الجهود العلمية الكبيرة للأنباري.

\section{أبو البركات الأنباري ودراساته النحوية}

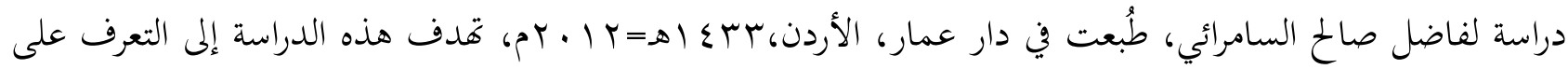

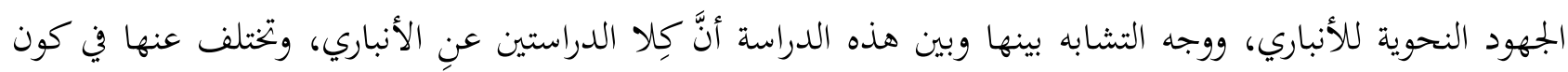

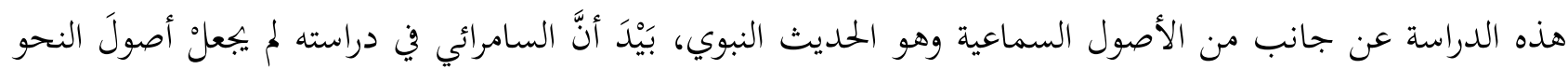

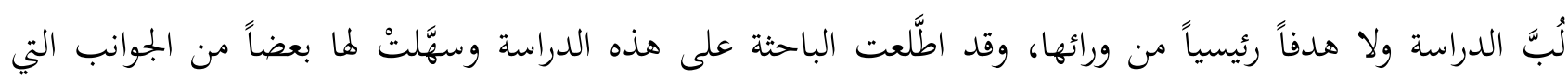

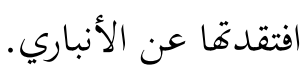

منهج ابن الأنباري في الاحتجاج من خلال كتاب (الإنصاف في مسائل الحلاف) 
دراسة تقدمت هما الباحثة: جريد سهيلة، لنيل درجة الماجستير في علوم اللسان العربي، جامعة قاصدي مرباح ورقلة، عام

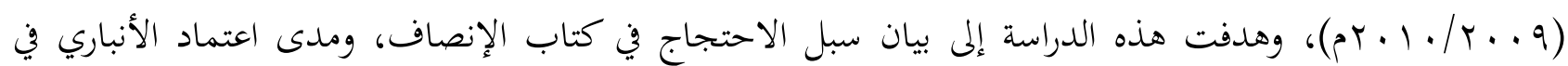

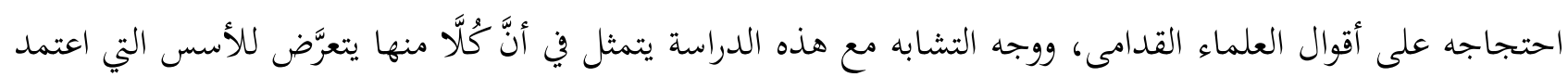

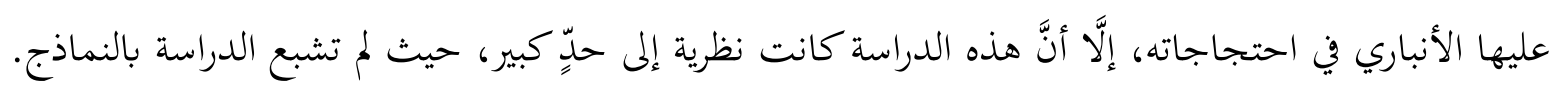

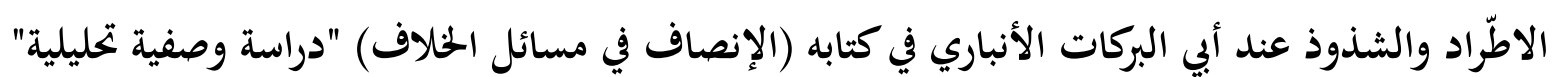

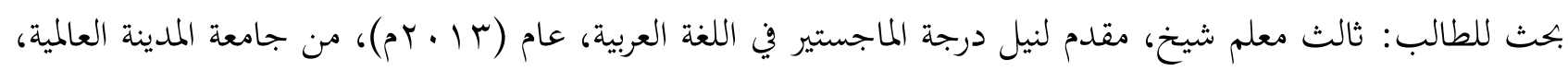

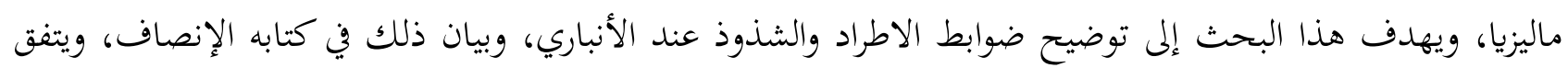
مع دراستي في موطن الدراسة وهي كتاب (الإنصاف).

المبحث الثالي: الإطار النظري

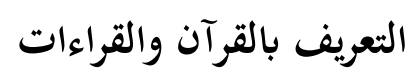

يقول الجرجاني في تعريفه للقرآن الكريم: "القرآن هو المنزل على الرسول، المكتوب في المصاحف، المنقول نقلاً متواتراً بلا

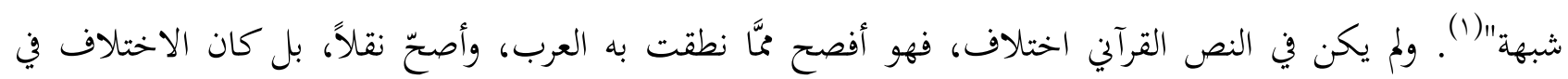

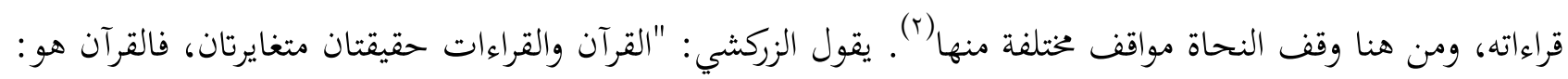

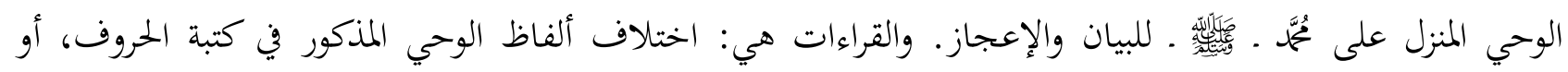
كيفيتها من تخفيف وتنقيل وغيرهما"(r).

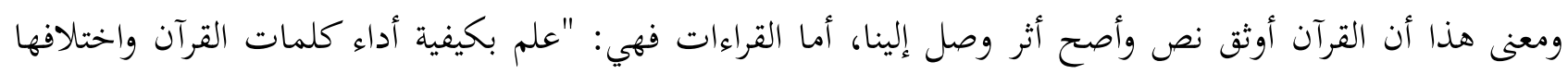

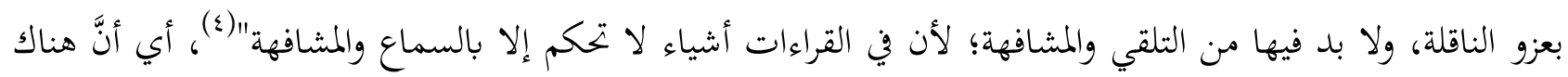

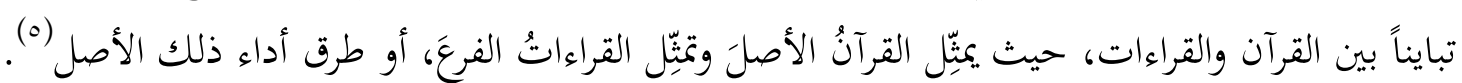

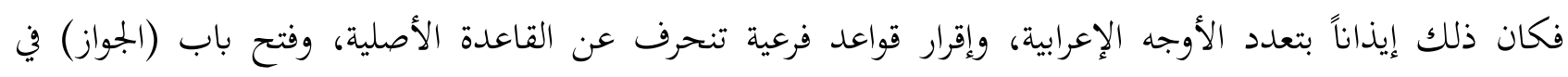

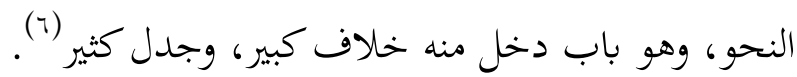

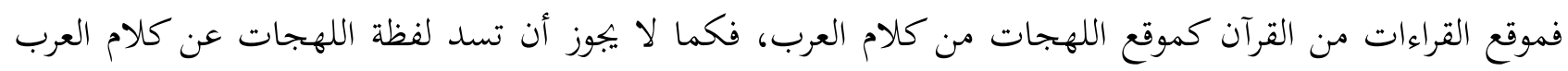

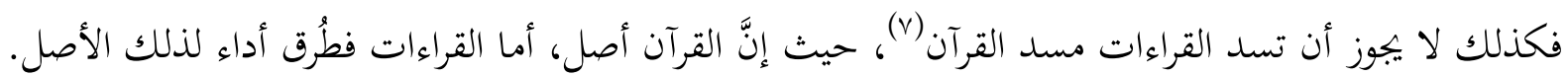

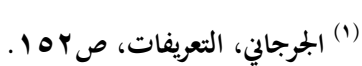

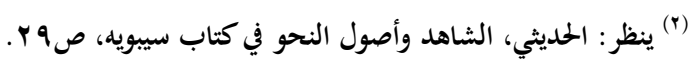

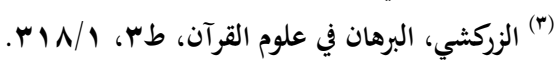

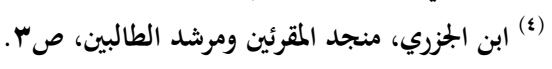

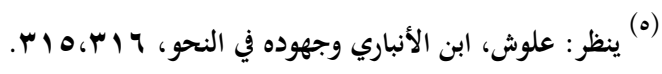

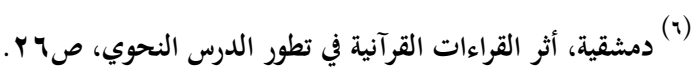

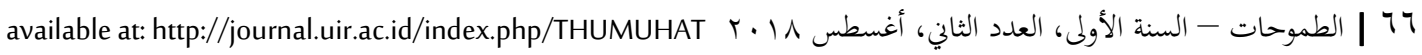


والإجماع معقود على أنَّ القرآن أحيط بالعناية والنقل الصحيح، حيث تحقق فيه شرط التواتر تحققاً ظاهرأ(ه)؛ ولِذا كان

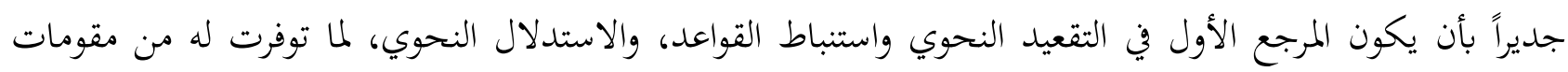

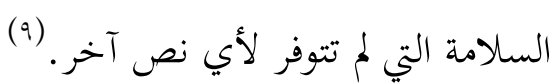

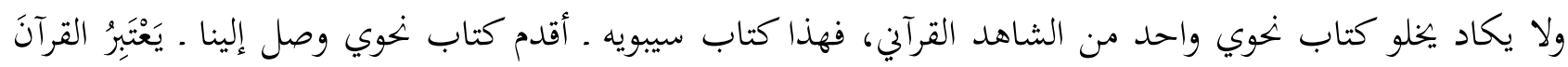

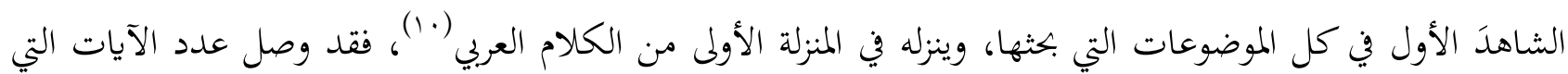

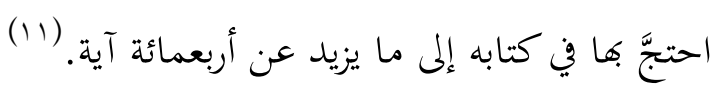

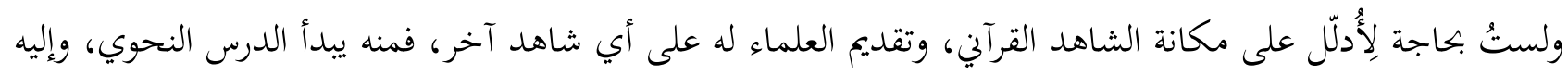

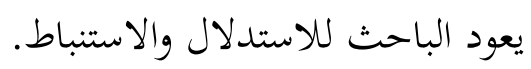
أما القراءات فقد قسمها العلماء إلى: "متواتر وآحاد وشاذ، فالمتواتر القراءات السبعة المشهورة، والآحاد قراءات الثلاثة

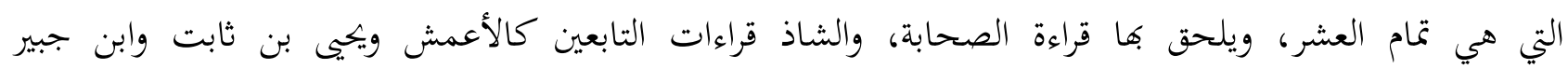

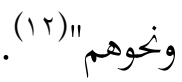

وقد فصّل علماؤنا القول في أقسام القراءات كالتالي (r) ): ا - القراءة المتواترة: وهي ما نقله جمع لا يمكن تواطؤهم على الكذب، عن مثلى مثلهم إلى منتهاه، وغالب القراءات كذلك. ץ- القراءة المشهورة: وهي ما صح سنده، ولم يبلغ درجة التواتر، ووافق العربية والرسم، واشتهر عند القراء، فلم يعدوه

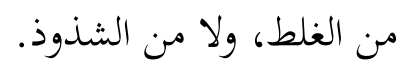
r- قراءة الآحاد: وهو ما صح سنده وخالف الثدود الرسم أو العربية، ولم يشتهر الاشتهار المذكور.

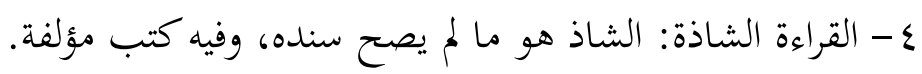
هـ - القراءة الموضوعة: كقراءات الحزاعي المنسوبة إلى أبي حنيفة.

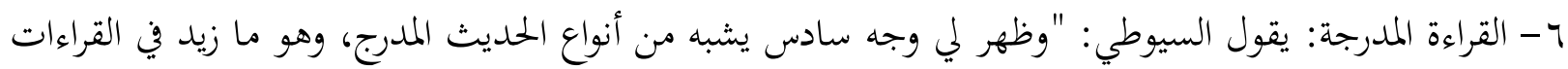

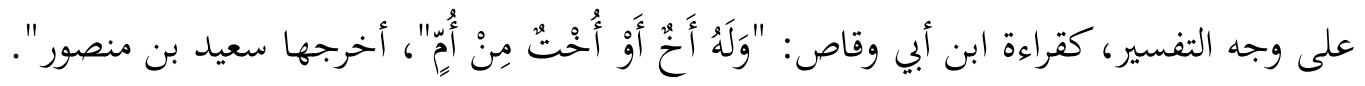

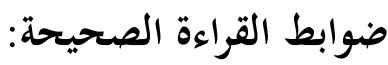

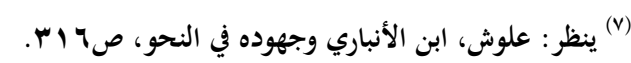

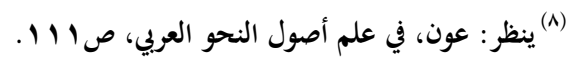

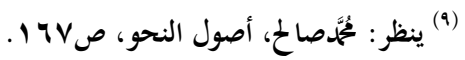

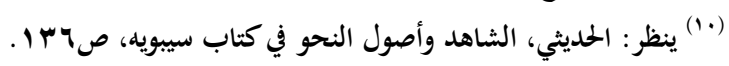

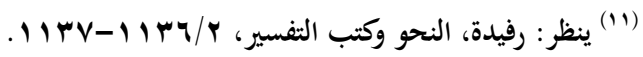

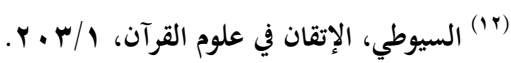

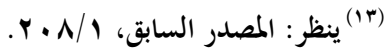

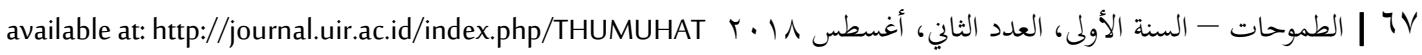


لم تكنِ القراءات القرآنية على درجة واحدة من الصحة والتواتر، ومن هنا وضع العلماء ضوابطَ للقراءة التي يُؤَخُْ هما، قال

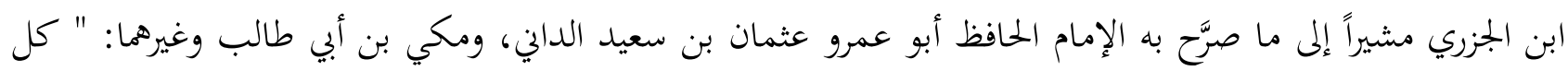

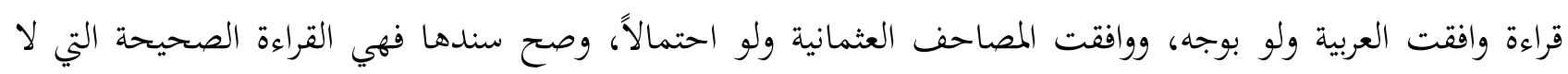

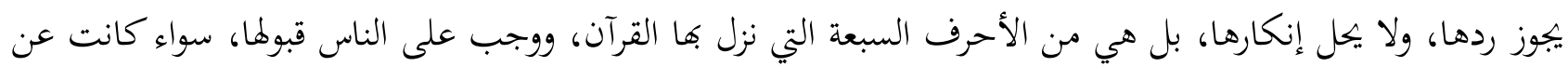

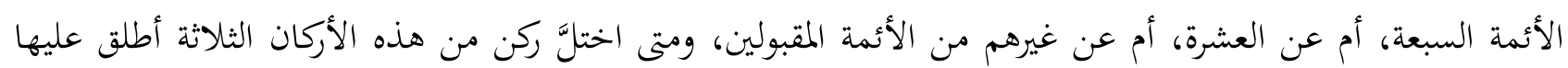

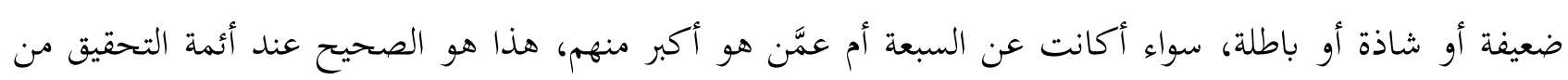

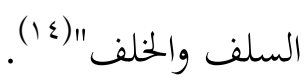

وعلى هذا فالعبرة في كون القراءة صحيحة تحقق تلك الضوابط فيها وليس من تُنسَب إليه تلك القراءة من القرّاء، وفي

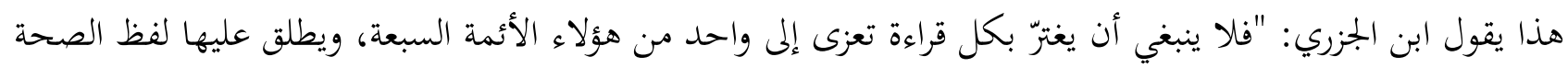

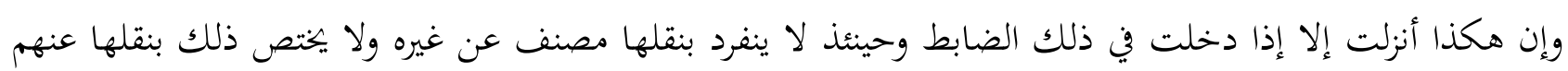
بل إن نقلت عن غيرهم من القراء فذلك لا يخرجها عن الصحة فإن الاعتماد على استجماع تلك الكأل الأوصاف لاف لا عمّن

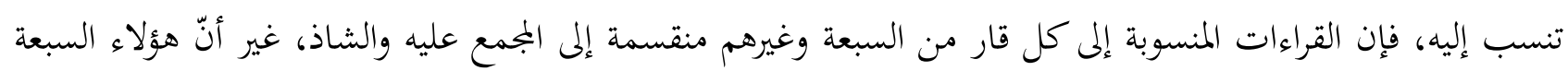

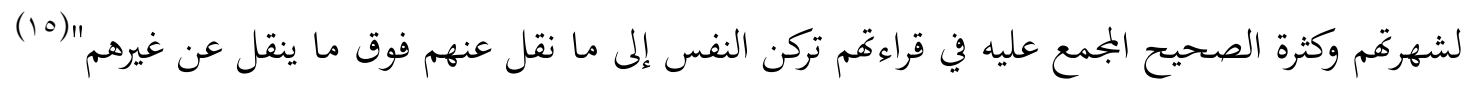
إذاً فالقراءة الصحيحة يشترط فيها: 1 - (1) صحة السند.

$$
\text { r- بوافقة الرسم العثماني ولو احتمالاً. }
$$

ويظهر للباحثة أنَّ شرط موافقة أحد المصاحف لا لا حاجةَ للنحوي بها، فلا ضررَ أن يعتمد النحويُّ على قراءة خالفت

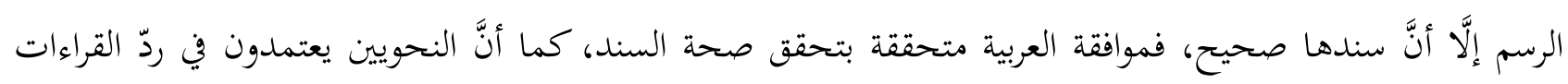

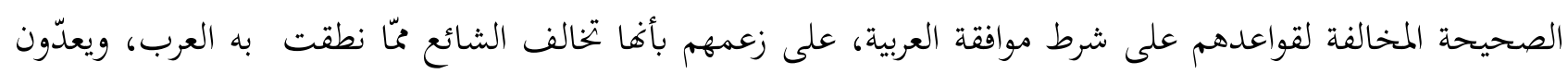

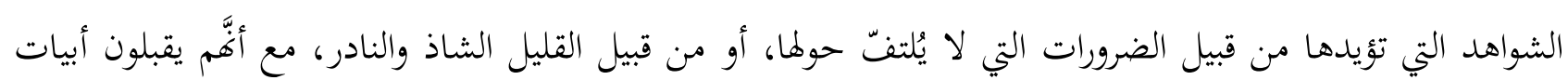

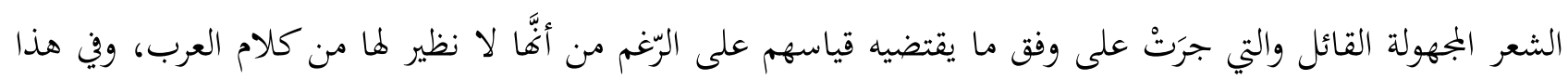

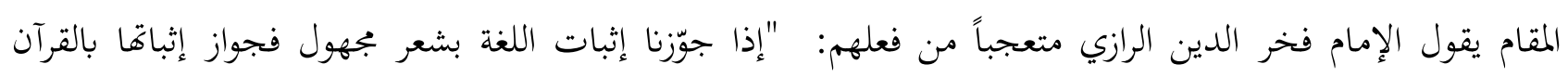

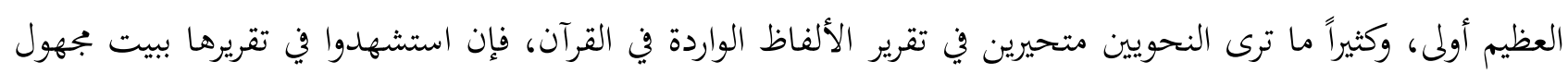

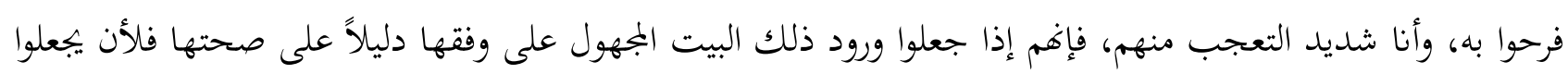

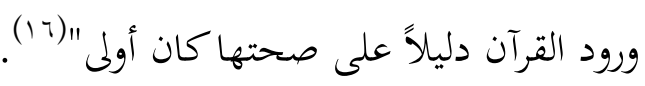

$$
\begin{aligned}
& \text { (1) ابن الجزري، النشر في القراءات العشر، 9/1) }
\end{aligned}
$$

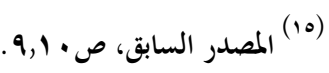

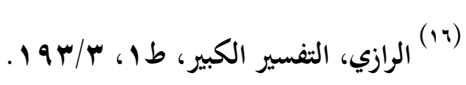


r- موافقة العربية ولو بوجه، أي أن توافق وجهاً نوياً، سواء أكان بجمعاً عليه أم مختلفاً فيه، فصيحاً أم أفصح، وهذا

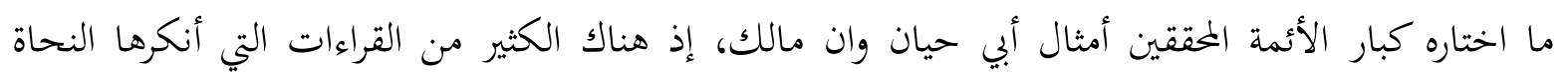

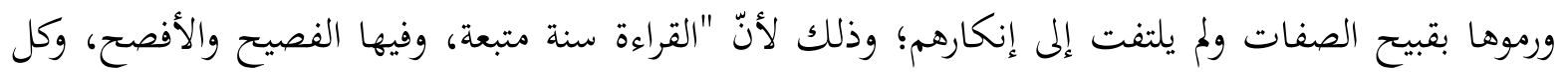

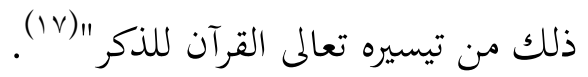

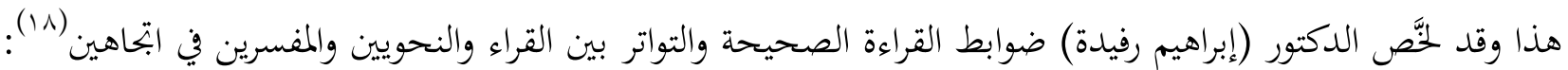

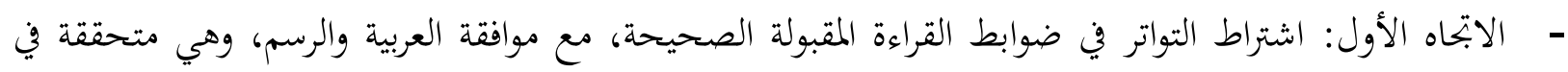

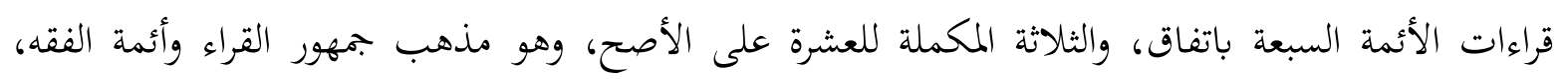
والمتأخرين من المفسرين والنحويين.

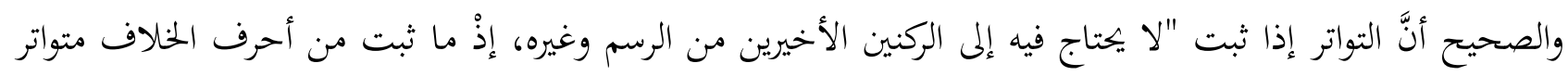

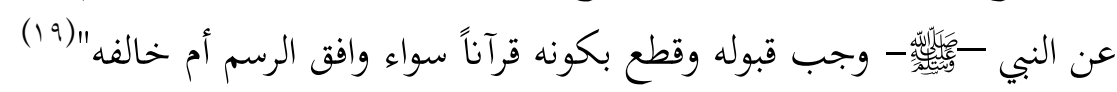

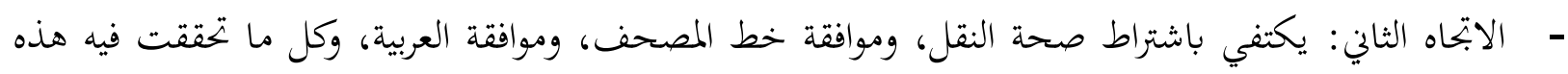

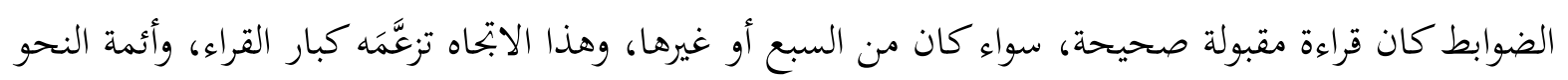
القدماء.

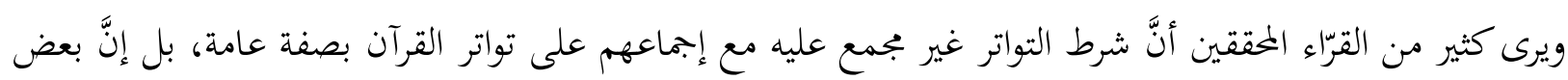

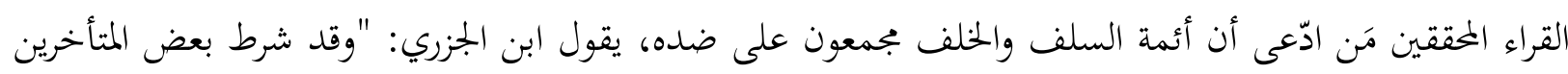

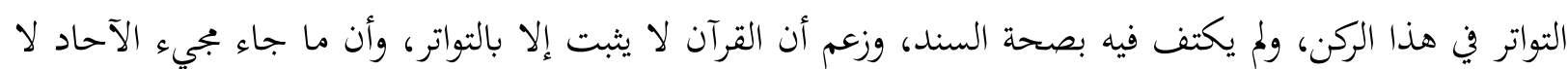

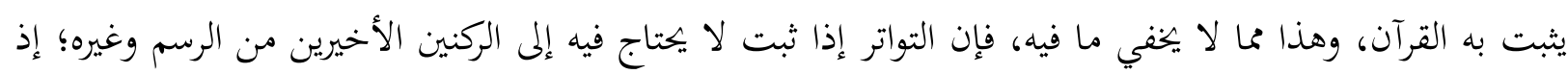

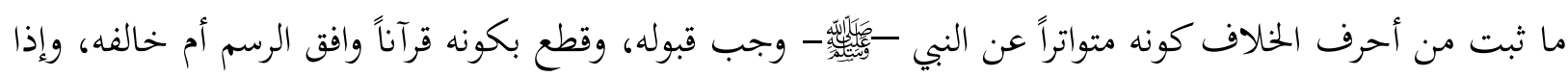

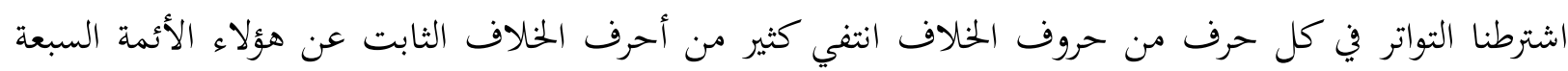

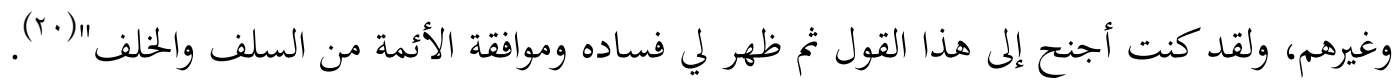

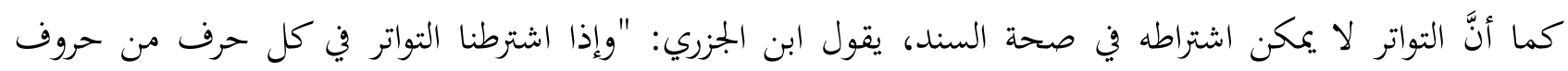

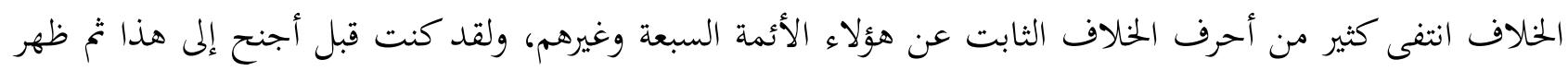

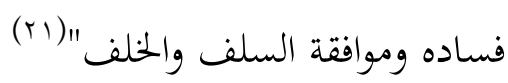

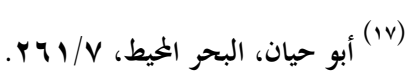

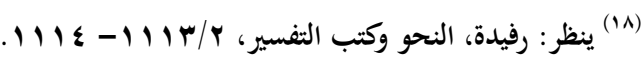

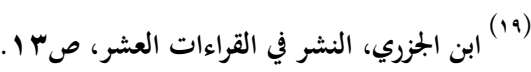

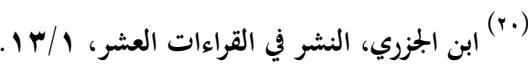

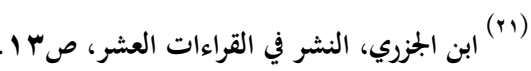


وعلى حين تشدّد القراء في صحة السند، وجعلوه معياراً أساسياً لصحة القراءة وقبولها تشدد النحويون في شرط موافقة العربية، حيث أدى تشبث بعضهم بهذا الشرط ـ في ظل تحكيم مقاييسهم وقواعدهم ـ إلى تخطئة بعض ما قرأه الثقات من

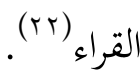
وعلى هذا فإن اختلَّ الشرط الأول (صحة السند) كانت القراءة باطلة، وإن اختلَّ الثاني (موافقة الرسم)كانت شاذة، وإن اختلَّ الثالث (موافقة العربية) كانت ضعيفة، فالقراءة لا تكون باطلةً إلاّ باختلال السند، يقول أحد الباحثين: "واختلاف صحة السند وحده هو الذي يجعل القراءة باطلة، أما ما عداه فيجعل القراءة ضعيفة أو شاذة، لكنها عند كثير منهم تظل صحيحة"(r).

\section{موقف النحاة من الاستشهاد بالقرآن والقراءات القرآنية.}

أثناء البحث مررتُ بمصطلحين يُستخدمان للدلالة على النصوص اللغوية التي كانت مصدر التقنين والتقعيد، وهما مصطلحا الاستشهاد والاحتجاج، وتبين للباحثة أنّ بينهما عموماً وخصوصاً "فالاستشهاد ذكر الأدلة النصية المؤكدة للقاعدة النحوية، أي التي تبنى عليها هذه القواعد، والاستشهاد - بهذا التحديد - بعض مدلول الاحتجاج، فإنَّ الاحتجاج هو الاستدلال على صحة القواعد النحوية مطلقاً، وبهذا الإطلاق يشمل كون الأدلة نصوصاً لغوية، أو أصولاً نجوية"(r) وقد وقفتِ الباحثة على كثير من الدراسات التي عرضت موقف النحاة من القراءات، فإذا بها ذات قواسم مشتركة، حيث إذها تعرض موقف النحاة النظري، ثم تتبع ذلك بمآخذ عليهم عند التطبيق.

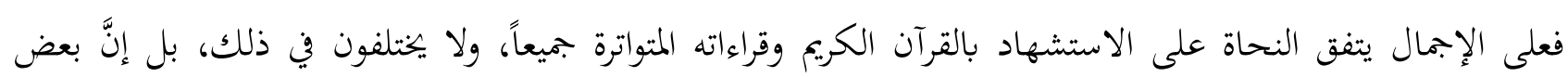
المتأخرين أجازوا الاحتجاج بالقراءات الشاذة على الرغم من أنَّ بعض المتقدمين منعوا ذلك، وأعماهم النحوية وكتبهم شاهدة على أفم بنوا النحو على كلام العرب الفصيح وفي مقدمته القرآن الكريم وقراءاته. وعلى هذا فعند الحديث عن موقف النحويين من الاحتجاج بالقرآن فلا يُقصد من ذلك النصّ الكلي الذي نزل به الوحي؛ لأنه لو قصد ذلك لما كان لأحد أن يجادل في الاحتجاج بآية منه، ولا يمكن أن يخضعه لأقيسته، وإنما المقصود بالقرآن عدد من القراءات التي قد يكون بين إحداها والأخرى خلاف في صوت أو لفظ أو تركيب نهوي لآية من آيات

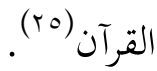

والحقّ أنَّه عند وضع القراءات القرآنية على رأس مصادر الاستشهاد يتبيّن لنا أنَّ هناك تبايناً كبيراً في موقف النحاة العملي، حيث كان لهم موقفان:

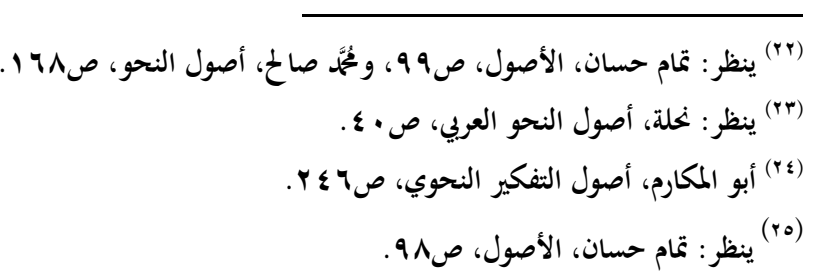

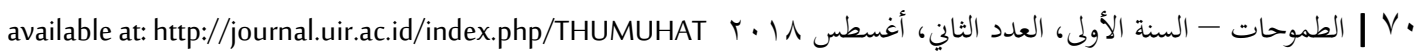


موقف مؤيد لها يرى الاعتماد عليها في الاحتجاج والتقعيد النحوي، ويغلب على أصحاب هذا المذهب الطابع النقلي،

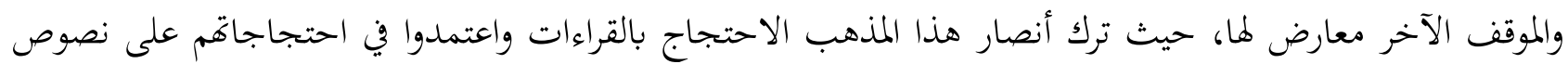

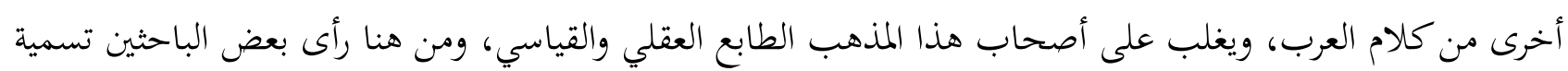

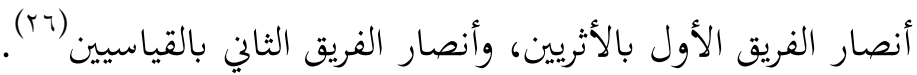
وقد وجدتُ كثيراً من المواقف النظرية لأئمة النحو منتشرة في مؤلفاقم منها:

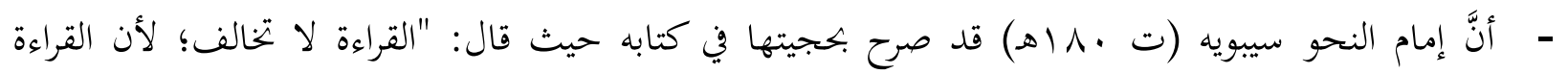

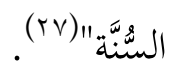

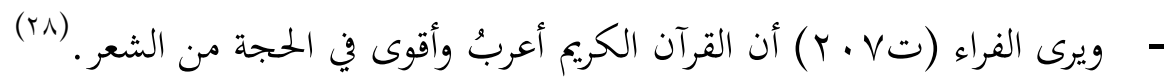

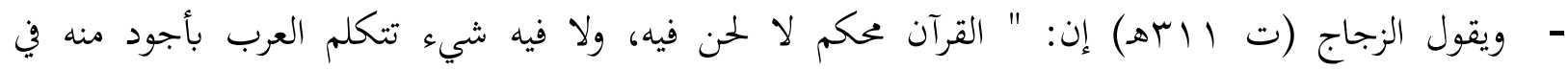

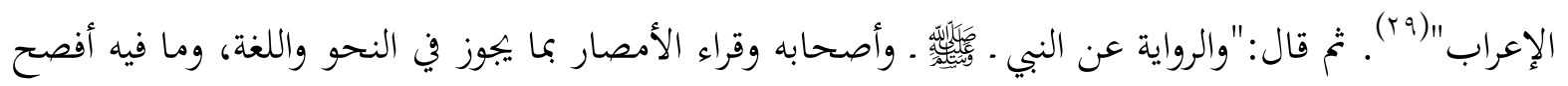

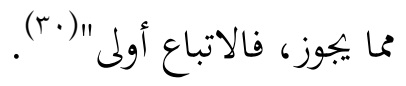

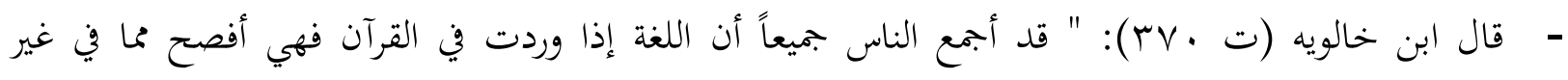

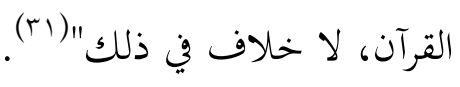

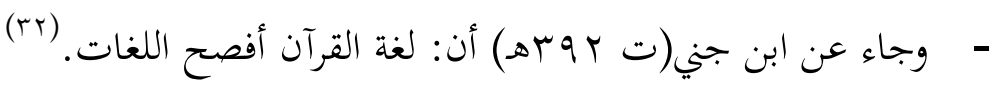

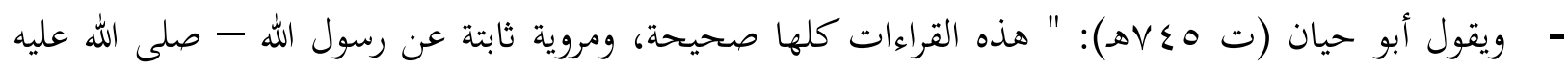

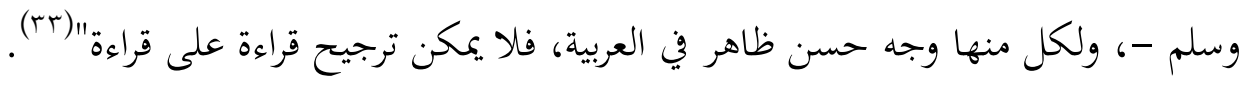

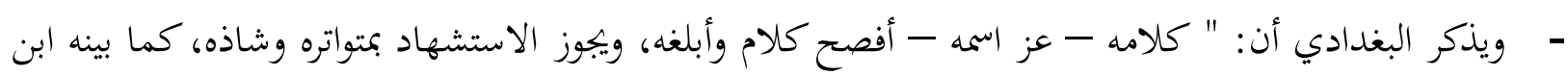

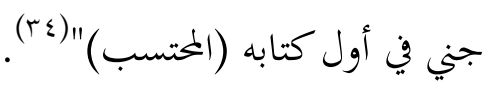

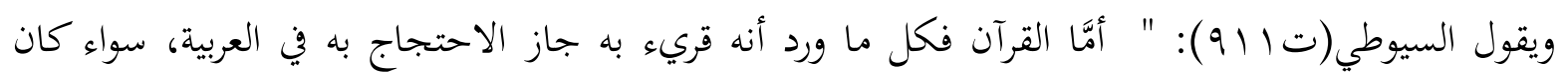
متواتراً أم آحاداً أم شاذاً، وقد أطبق الناس على الاحتجاج بالقراءات القات الشاذة في العربية إذا لم تخالف قياساً

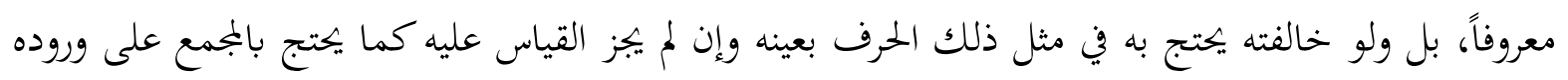

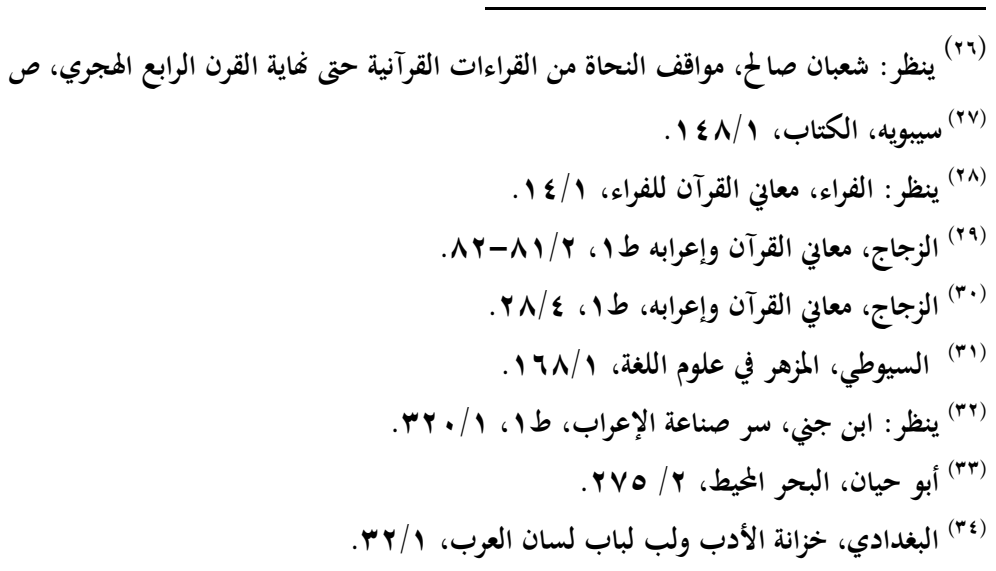

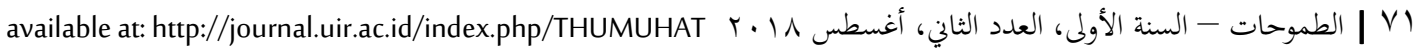


و مخالفته القياس في ذلك الوارد بعينه ولا يقاس عليه نخو: استحوذ، ويأبى، وما ذكرته من الاحتجاج بالقراءات

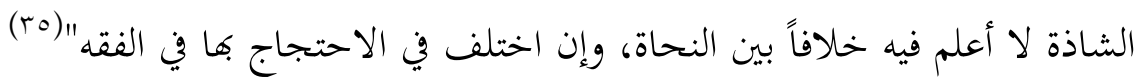

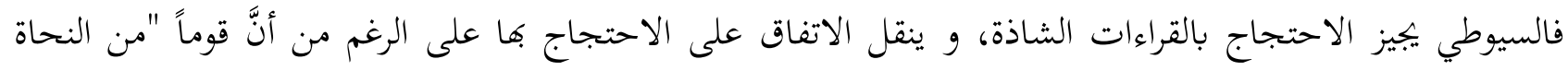

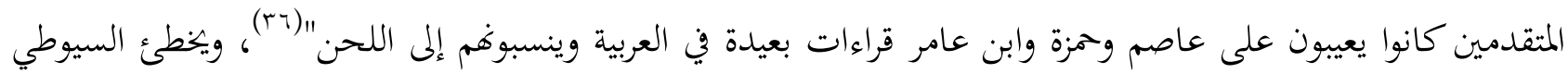

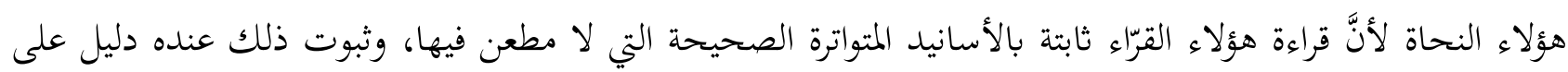
جوازه في العربية(rv) فهذه أقوال بعض أئمة النحو واللغة توضح الموقف النظري للنحاة من الاستشهاد بالقرآن الكريم وقراءاته، وهي بلا شك تضع النص القرآين والقراءات القرآنية في موضعها اللائق.

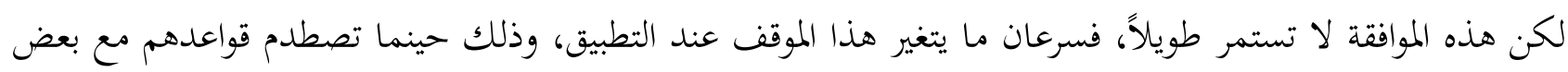

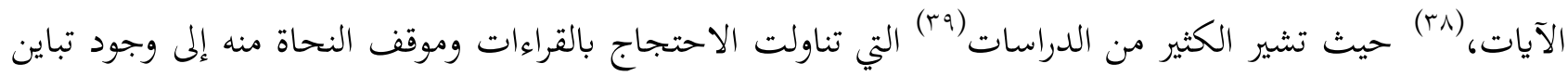

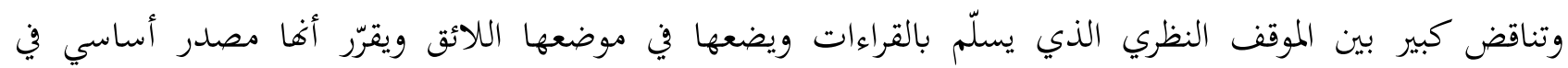
الاحتجاج، وبين الموقف التطبيقي العملي. حيث كان موقف النحاة من القراءات -عند التطبيق- مضطرباً، فهم لا يعترفون ولا يقرون بالشروط التي وضعها القورّاء،

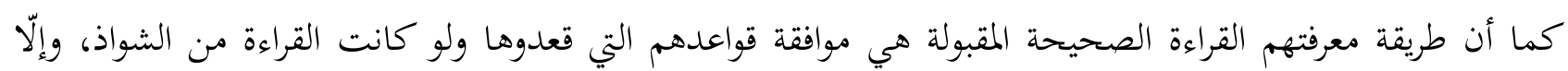

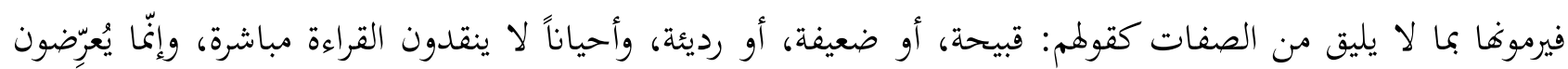

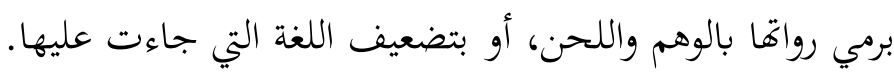

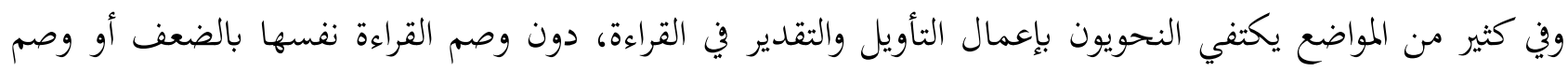

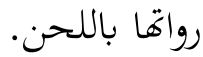
ويذكر كثير من الباحثين والدارسين(.) أنّ الكوفيين يتقبلون كل القراءات: شاذها وآحادها ومتواترها، ويعتمدون عليها

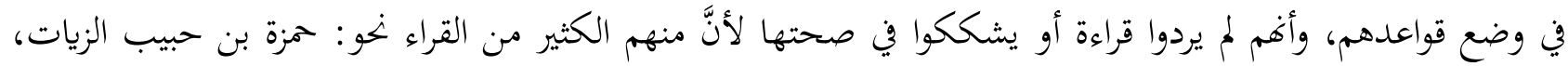

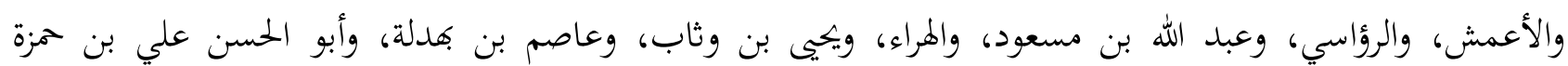

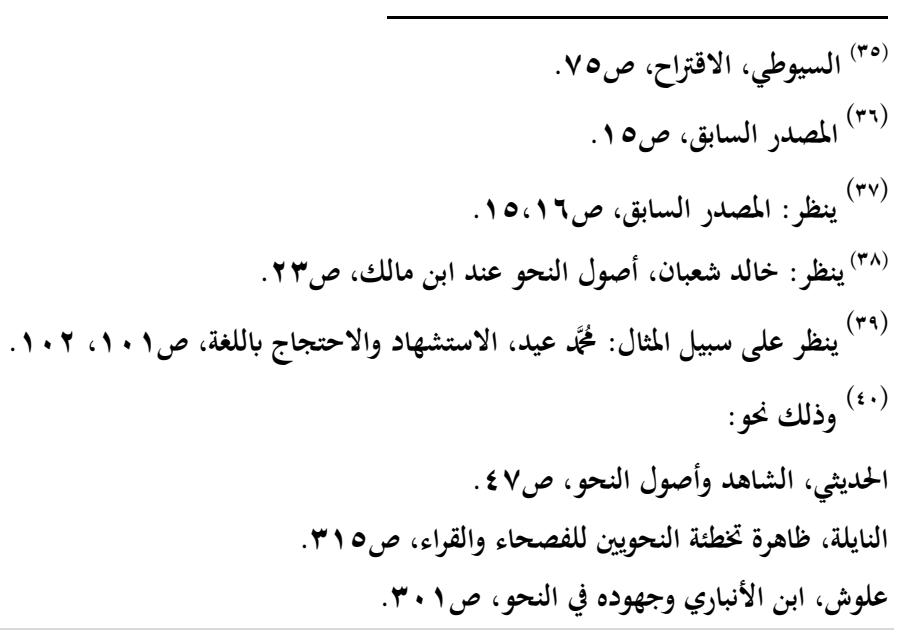

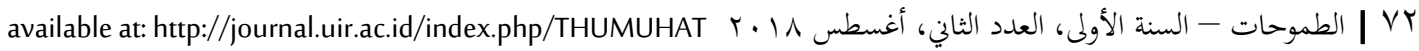


الكسائي، وزر بن حبيش، أبو عبد الرمن السلمي وغيرهم، وأغم كانوا معتمدين على الشروط الثلاثة التي وضعها القراء

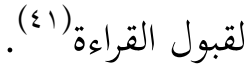
ولعلَّ الأصوب أن يُقال إن هذا الموقف من القراءات -التأويل والتقدير - كان موقف النحويين جميعاً -بصريين وكوفيينبلا استثناء.

وقد زعم الدكتور شوقي ضيف أنَّ الاعتماد على القرآن الكريم وقراءته في التقعيد كان منهج نحاة البصرة المتقدمين. (זی) وفي هذا يقول الدكتور إبراهيم عبد الله رفيدة: "يتفق النحويون على الاستشهاد بالقرآن الكريم وقراءاته المختلفة: متواترها

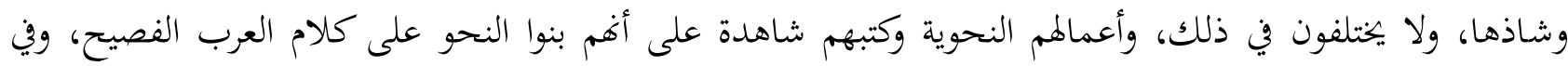

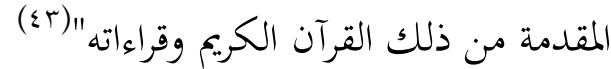
فعلى سبيل المثال يقول نصر بن عاصم في قراءة عروة بن الزبير: "قل هو الله أحد" بتنوين (أحد): "بئس ما قال، وهو

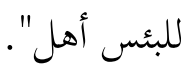

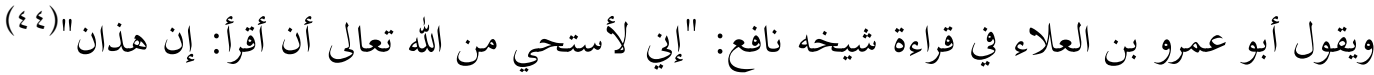

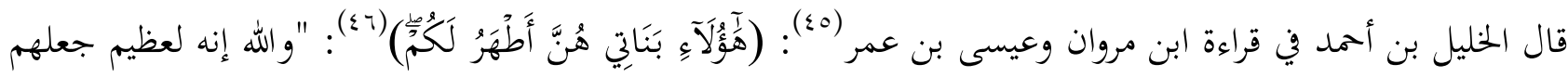

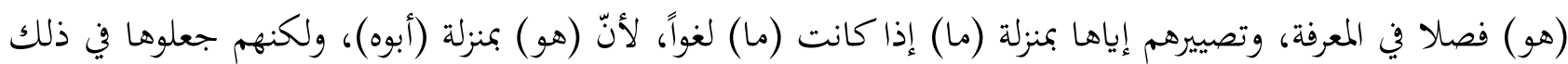

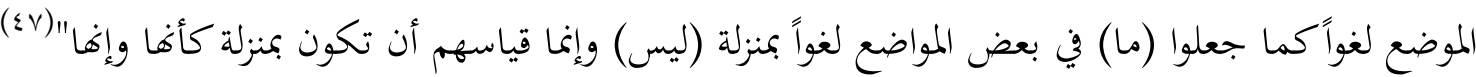

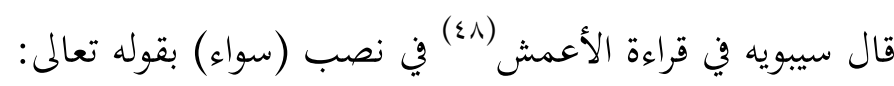

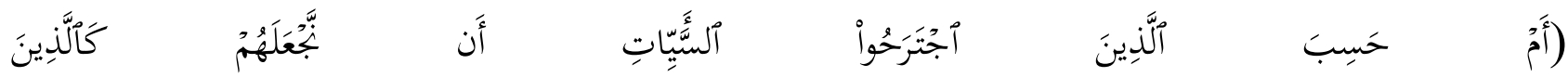

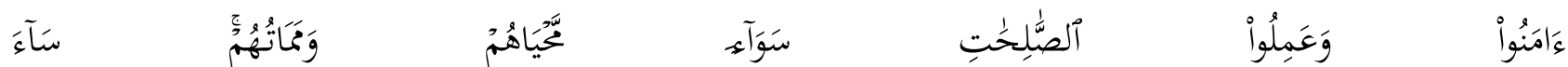

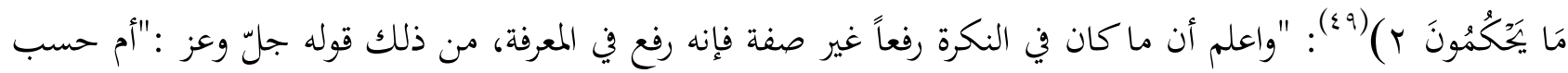

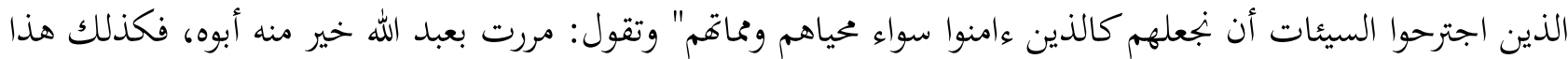

$$
\begin{aligned}
& \text { ينظر : السامرائي، التطور التاريخي واللغوي، طب، ص9ه. }
\end{aligned}
$$

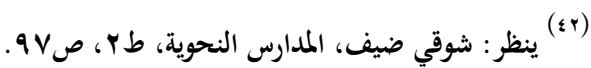

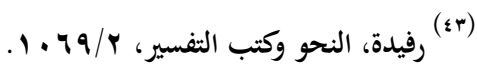

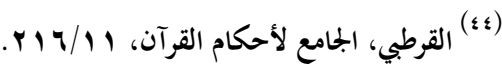

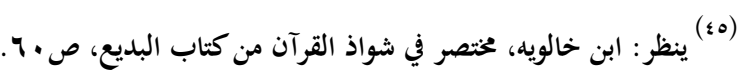

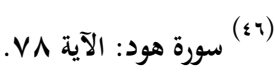

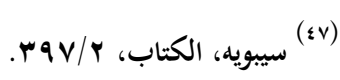

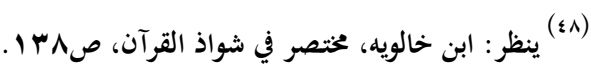

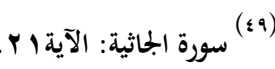


وما أشبهه، ومن أجرى هذا على الأول فإنه ينبغي له أن ينصبه في المعرفة فيقول: مررت بعبد الله خيراً منه أبوه، وهي لغة رديئة|"(0.)

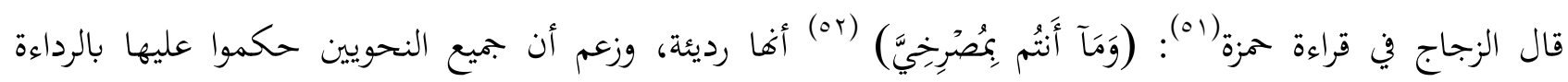
والرذالة(م)

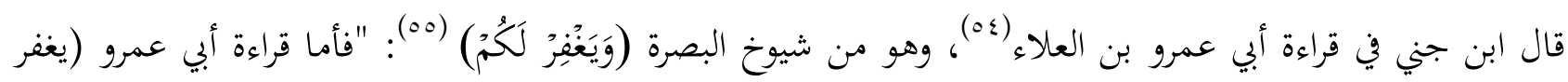
لكم) بإدغام الراء في اللام فمدفوع عندنا، وغير معروف عند أصحابنا، إنما هو شئ رواه القراء ولا قوة له في القياس" (جنه ويرى بعض الباحثين أنَّ للمذهب النحوي أثراً في الاستشهاد بالقراءات، إذ يصمون البصريين بأفم يقبلون جميع القراءات

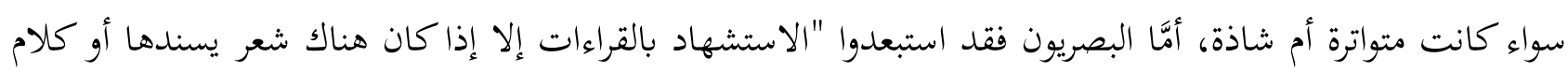
عربي يؤيدها أو قياس يدعمها" (Vo) ، و "خلاصة الرأي في استشهاد نحاة البصرة على وجه العموم بالقراءات أفم كانوا

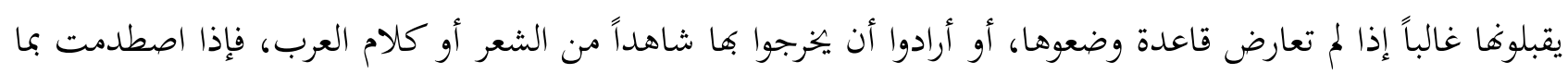
وضعوه من قواعد فإحدى ثلاث: إما التأويل والتخريج، وإما تضعيفها والطعن عليها أو على من قرأ بها، وإما إغفالها

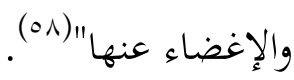
أمَّا ما ذكره السيوطي من إطباق الناس على الاحتجاج بالقراءات الشاذة بقوله"وقد أطبق الناس على الاحتجاج بالقراءات الشاذة في العربية إذا لم تخالف قياساً معروفاً..."(هوه) فأمر فيه نظر وتعميم كبير، يقول الدكتور محمود نحلة:

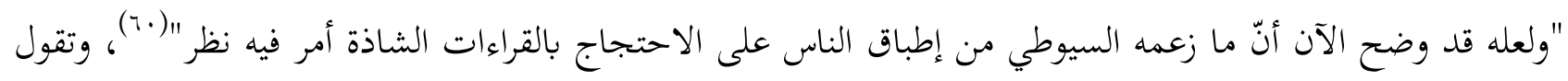
الدكتورة خديجة الحديثي: " ولم يكن من منهج البصريين الاستشهاد بالقراءات الشاذة"|(1آ).

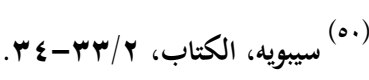

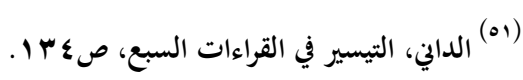

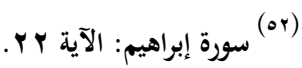

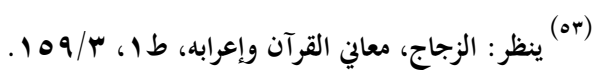

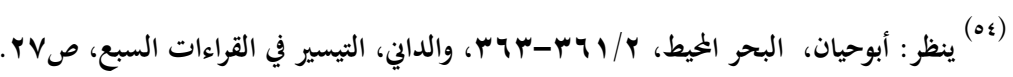

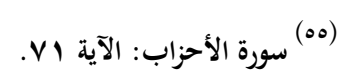

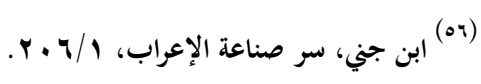$$
\text { (ov) }
$$

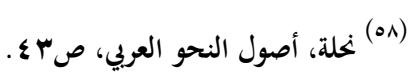

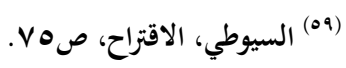

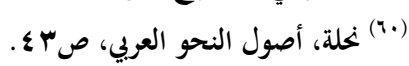

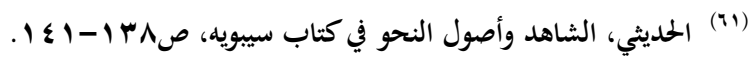

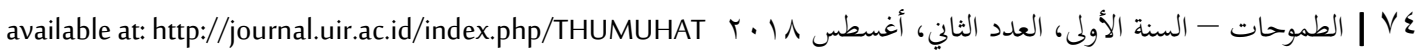

